\title{
Erratum to: Apathy in untreated, de novo patients with Parkinson's disease: validation study of Apathy Evaluation Scale
}

\author{
Gabriella Santangelo $\cdot$ Paolo Barone $\cdot$ Sofia Cuoco $\cdot$ Simona Raimo $\cdot$ Domenica Pezzella $\cdot$ \\ Marina Picillo - Roberto Erro - Marcello Moccia - Maria Teresa Pellecchia - Marianna Amboni - \\ Franco Santangelo $\cdot$ Dario Grossi $\cdot$ Luigi Trojano $\cdot$ Carmine Vitale
}

Published online: 9 October 2014

(C) Springer-Verlag Berlin Heidelberg 2014

\section{Erratum to: J Neurol \\ DOI 10.1007/s00415-014-7498-1}

In the original article, one of the co-author's (Franco Santangelo) given name and family name are represented incorrectly. The correct name should be Franco Santangelo.

The online version of the original article can be found under doi:10.1007/s00415-014-7498-1.

G. Santangelo $\cdot$ S. Cuoco - S. Raimo - D. Pezzella $\cdot$ D. Grossi

L. Trojano $(\square)$

Department of Psychology, Second University of Naples, Caserta, Italy

e-mail: luigi.trojano@unina2.it

G. Santangelo $\cdot$ M. Amboni $\cdot$ C. Vitale

IDC-Hermitage-Capodimonte, Naples, Italy

P. Barone $\cdot$ S. Cuoco $\cdot$ M. Picillo $\cdot$ M. T. Pellecchia

Department of Medicine and Surgery, Neurodegenerative

Diseases Center, University of Salerno, Salerno, Italy

R. Erro

Dipartimento di Scienze Neurologiche e del Movimento,

Università di Verona, Verona, Italy
R. Erro

Sobell Department of Motor Neuroscience and Movement

Disorders, University College London (UCL) Institute of

Neurology, London, UK

M. Moccia $\cdot$ F. Santangelo

Department of Neuroscience Reproductive and

Odontostomatologic Sciences, University of Naples Federico II,

Naples, Italy

C. Vitale

University Parthenope, Naples, Italy 